\title{
Seeing the forest, beyond the trees: dimensionality of context specific Organizational Citizenship Behaviour in a Sri Lankan context
}

\author{
Hansiya Abdul Rauf ${ }^{1}$ and Shamala Kumar ${ }^{2 *}$ \\ ${ }^{I}$ Postgraduate Institute of Agriculture, University of Peradeniya, Peradeniya. \\ ${ }^{2}$ Postgraduate Institute of Management, 28, Lesley Ranangala Mawatha, Colombo 08.
}

\begin{abstract}
Factor analyses of existing measures of Organizational Citizenship Behaviour (OCB) administered across different contexts and country settings demonstrate cross-setting consistency and support a common dimensionality for OCB irrespective of context. Challenging the use of generic models of OCB are concerns over the local relevance of such generic models and the substantial variation in OCB dimensionality in different country settings found through research using inductive qualitative methods. Even though these findings give conflicting understandings of the context specificity of $\mathrm{OCB}$, a review of literature found no studies that subjected qualitatively derived dimensions to factor analysis. This research uses factor analyses to test a qualitatively derived, context-specific OCB model to explore the context specificity of OCB. University academic staff in Sri Lanka participated in two studies. Findings support a generally accepted two-factor model and not the context specific model. The findings suggest that even when high contextual variations in constructs seem evident, conceptual similarity at a more general level may be present. Past research exploring OCB conceptualisations have used either qualitative or quantitative methods. While qualitative methods indicate complex and contextually specific dimensions, quantitative methods support simpler models with more general applicability. The findings suggest that even when the model and items are localised, factor analyses support a general OCB model.
\end{abstract}

Keywords: Organizational Citizenship Behaviour, factor structure, Sri Lanka, emic and etic, culture.

\section{INTRODUCTION}

Organizational Citizenship Behaviours (OCB) are behaviours that support the social and psychological environment in which task performance takes place (Organ, 1997). OCBs have received much attention within human resource management because they are associated with organizational effectiveness, in terms of indicators ranging from higher customer satisfaction to greater profitability (e.g., Podsakoff et al., 2009; Sun et al., 2007). Because they have substantial bearing on employee performance ratings (Podsakoff et al., 2009), OCBs are central to human resource management.

Evidence of the significance of OCB is demonstrated in research conducted in many settings, including in Sri Lanka. Among school teachers in Sri Lanka, perceptions of justice and teacher empowerment were found to be a predictor of organizational citizenship behavior (Anuja, 2016; Rauf, 2014; Rauf, 2015a, Rauf, 2015b). OCB directed toward other employees was found to predict performance and OCB mediates the relationship between perceived organizational support and performance quality among shop floor employees at ISO 9001:2000 certified manufacturing firms in Sri Lanka (Wickramasinghe \& Perera, 2014). OCB also predicted work alienation (Rauf, 2015b). Another study

*Corresponding author (kumar.shamala@gmail.com; (iD https://orcid.org/0000-0002-6368-218X) 
conducted in Sri Lanka found that OCB is positively related to work-family conflict but that the effect was moderated by work-family conflict efficacy (Rauf, 2013). Among a sample of 224 Sri Lankan employees supported that organizational justice is related to organizational citizenship behavior, and employee work alienation is demonstrated to be a mediator in this relationship.

As OCBs are described as highly grounded in the context in which they occur (Organ, 1998; Organ et al., 2006), understanding how they vary across cultural contexts is particularly important. However, the literature on OCB across regions and cultures show varying degrees of consistency in the dimensionality of the construct. In this paper, the researchers explore the context specificity of OCB by subjecting a highly contextually grounded set of OCB items, designed to capture contextually grounded OCB dimensions, to analytical methods that generally demonstrate high consistency in dimensions. By doing so, the extent to which variability in dimensionality is associated with methodology is explored.

Although much of the initial work on OCB was conducted in North America (Podsakoff et al., 2000), a growing body of literature is based in other regions (a Google Scholar search for 'organizational citizenship behaviour' and 'cross cultural' from 2013-2016 resulted in over three times as many hits as it did for the period between 2007-2009). Much of this research simply borrows early conceptualisations of OCB, such as Organ (1998), and uses translated versions of existing scales such as Podsakoff et al. (1990). Other research uses existing scales, but attempts to establish measurement equivalence in the new context generally through factor analysis and other methods (e.g.; Takeuchi et al., 2015; Zhao et al., 2012). Both these sets of studies demonstrate consistency in OCB dimensions across settings. A final set of studies have attempted to ground their research in the new context and to develop conceptualisations endemic to local settings (e.g., Farh et al., 2002; Rauf \& Kumar, 2015). These latter studies report a range of OCB dimensions and suggest a large variation across settings. The dimensions developed through this final set of studies seem to, however, have not been subjected to model testing using factor analytical methods.

\section{The purpose and scope of the study}

The present study explores the factor structure of an OCB measure for Sri Lankan university academic staff derived using inductive methods and designed to capture dimensions that were specific to that context to ascertain whether these dimensions are robust when subjected to factor analysis. The study attempts to address how research generated from two different perspectives may provide different perspectives of a single construct and how these findings may be interpreted. This research is not meant to validate a scale and therefore, does not address scale equivalence and other concerns (Hui \& Triandis, 1985) that should be addressed in a validation study. This study focuses on classical conceptions of OCB (e.g., Katz \& Kahn, 1966; Organ, 1988), on which later extensions of the construct are derived (e.g., Boiral, 2009; Nohe \& Michaelis, 2016).

\section{ETIC AND EMIC APPROACHES TO ORGANIZATIONAL BEHAVIOUR}

An on-going debate on the nature of psychological phenomena and the extent to which constructs remain comparable across cultural settings becomes significant as organizations expand geographically. Berry (1969), warns against research carried out assuming that constructs remain largely transferable across cultures, referring to such research as using an imposed etic approach. The extent to which the locality might affect the nature and importance of a construct and how the context may influence the nomenological network associated with it remain unaddressed in research that unquestioningly transplants theories and tools to new contexts.

Even within research that does not simply ignore the possibility of differences between cultural contexts, the understanding of what such differences mean with respect to conceptualisation and methodology vary. Within a cross cultural paradigm, emphasis is placed on understanding and theorising differences between cultures, and, as a result, dimensions have been identified along which cultures differ, such as Hofstede's (1980) value orientations (see also Norenzayan \& Heine, 2005, for a review). While this research may acknowledge the role of cultural differences, if measures developed elsewhere are used with little attention to their relevance in the new setting, the research would still be based on an imposed etic approach. To be truly effective, an etic approach, which seeks generalities or universals across cultures, would require establishing equivalence in the constructs used to compare groups.

Research emanating from cultural or indigenous psychological frameworks (Ratner, 2008) emphasises developing contextualised and historicised understandings of phenomena, with comparisons across cultures, at the most, a secondary concern (Ratner, 2008). Much of this research would follow an emic approach and put greater emphasis on locally derived conceptualisations of constructs. However, irrespective 
of paradigm (cross-cultural, cultural or indigenous), ultimately this research reflects endeavours to develop comprehensive understandings of phenomena even though they differ in the process of arriving at such understandings. Cross-cultural methods would use crosscultural comparisons to identify differences in phenomena across contexts; thereby ultimately allowing for theories that would be able to explain these differences (Ho \& $\mathrm{Wu}, 2001)$. Cultural and indigenous paradigms would begin by exploring the distinct nature of the phenomena within a context to later develop a more comprehensive understanding, which is perhaps more nuanced than those developed through cross-cultural methodologies (Chakkarath, 2012).

As these approaches, founded on different epistemological traditions, use different processes to achieve similar objectives, the methods used also differ. Cross-cultural research adopts a positivist epistemological position and tends to use quantitative indicators of difference and similarity. Statistical equivalence is frequently used to establish similarities in conceptualisations and measures. The other approaches, in contrast, are likely to use qualitative methods to identify the nature of phenomena in a particular context. Because their approaches to research differ, it is likely that the nature of the findings from the different approaches may yield results that are different in scope and make the ability to draw on both bodies of literature to arrive at a comprehensive understanding of the world challenging. This paper uses Organizational Citizenship Behaviour $(\mathrm{OCB})$ as a focal construct to explore this proposition.

\section{OCB DIMENSIONALITY}

The literature on OCB has its roots in North America and includes a number of conceptualisations of OCB (see Podsakoff et al., 2000), which are generally implicitly framed as universal even though such generalisations are problematic (see Podsakoff et al., 2000). Two conceptualisations stand out in the literature. The first, developed by Organ (1988), is significant as it is the first to have been introduced, and therefore, the basis on which many later models were built. Williams \& Anderson's (1991) two-factor solution is significant for its parsimony and popularity.

Organ's (1988) original model, identifies five dimensions of OCB, in which employees engage at their discretion: altruism, behaviour targeted to helping a specific other with an organizationally relevant problem; conscientiousness, behaviour that goes beyond minimum organizational role requirements related to aspects such as attendance, obeying rules and regulations, and taking breaks; sportsmanship, willingness to tolerate less than ideal circumstances without complaining; courtesy: behaviours aimed at preventing work related problems with others from occurring; civic virtue, behaviour that indicates an employee's participation, involvement and concerns about the company. Podsakoff et al. (1990) developed a widely used measure based on the model by generating items that fit definitions of the five dimensions through subject matter experts. They then used a Q-sort method and factor analysis to validate the dimensions.

Williams \& Anderson's (1991) two component model categorises OCB into (a) OCBO, behaviours that benefit the organization directly, and (b) OCBI, behaviours that benefit specific individuals and only indirectly benefit the organization (Dalal, 2005; Organ \& Paine 1999). Several measures have been developed based on a two dimensional conceptualisation, all of which used factor analytic procedures to do so (e.g., Smith et al., 1983; Williams \& Anderson, 1991). The OCBI-OCBO conceptualisation is widely used (Weikamp \& Göritz, 2016) and supported empirically (Bourdage et al., 2012). The two dimensions seem to result from different concerns, with OCBI associated with prosocial concerns and OCBO associated with more organizational and impression management concerns (Bourdage et al., 2012; Finkelstein, 2006; Finkelstein \& Penner, 2004; Rioux \& Penner, 2001).

\section{CONCEPTUALISATIONS OF OCB IN THE CULTURAL AND CROSS-CULTURAL LITERATURE}

The literature exploring the dimensionality of $\mathrm{OCB}$ across regions addresses the extent to which OCB conceptualisations are similar or different across cultures. Two predominant themes seem to characterise this literature. The first focuses on the extent to which perceptions of OCB and in-role behaviour differ across cultures. Demarcating the scope of one's job does not seem to depend solely on the content of one's job description but varies as a function of other factors such as context (Graen, 1976). Of the latter, the sociocultural setting is important to consider. Generally, this research indicates that Confucian Asian settings (e.g., China, Japan, Singapore), which constitute a substantial proportion of the non-Anglo populations studied, have broader conceptions of their job role than Anglo settings (e.g., United States, Australia, England), meaning that some of what Anglo participants may view as OCB would be viewed as task performance in Confucian Asian settings (Lam et al., 1999). 
The second theme, which is of more relevance to the present research, examines the extent to which OCB dimensions are universal, or etic in conception. Some of these studies, which are designed to establish measurement equivalence across settings, indicate a common structure across populations (e.g., Lam et al., 1999; Takeuchi et al., 2015). Many of these studies, which use factor analytic methods, indicate that conceptualisations of OCB transcend countries and even continents (even though these studies hypothesise somewhat different dimensional structures from each other). Other studies, which are rather limited, are attempts to inductively identify OCB dimensionality (Farh et al., 1997; Farh et al., 2002; Kumar \& Bakhshi, 2009; Rauf \& Kumar, 2015; Yutaka \& Atsuko, 2011).

Studies that attempt to use inductive methods to determine dimensionality, again fall into two categories. Some studies determine dimensionality through factor analysis of items derived inductively, while others use qualitative methods of grouping to do so. To illustrate the former type of research, Farh et al. (1997), in Taiwan, initially developed OCB items through a sample of MBA students and then used exploratory factor analysis to identify five dimensions. Of these dimensions, three were described as etic (universal) as they parallel dimensions identified in Organ (1988): identification with company (similar to civic virtue), altruism and conscientiousness. The additional two, interpersonal harmony; actions aimed at facilitating and preserving harmonious relations, and protecting company resources; actions that save company resources, were described as emic (culture specific). This conceptualisation of OCB and the associated measurement tool has been the most extensively used of those derived from Asian contexts (e.g., Lam et al., 2009; Zhao et al., 2012). However, Zhao et al. (2012) provide evidence through a series of studies, to suggest that the two culture specific dimensions identified by Farh et al. (1997) are simply the positive end of deviant behaviours and should not be classified at OCB. Similarly, in India, Kumar \& Bakhshi (2009) generated items through an interviewing process. Principal components analysis was used to identify dimensions. Five dimensions were identified, similar to those that had already been described in the literature: conscientiousness, helping co-workers, group activity participation, sportsmanship and courtesy.

Other studies, in contrast do not use factor analysis at all, and have both generated items inductively and then again use inductive methods to identify dimensions. Farh et al. (2004) examined the dimensions of OCB using a Hong Kong based sample. They used a purely qualitative classification system and arrived at 10 dimensions of OCB, of which five had already been identified [cf. taking initiative (similar to conscientiousness), helping co-workers (similar to altruism or helping), voice (similar to voice in the extant research but broader), participation in group activities (similar to civic virtue) and promoting company image (similar to loyalty)]. They reported the additional dimensions: self-learning, which refers to improving one's own knowledge or working skills; social welfare participation, which refers to employees' participation in activities of public welfare or community service; keeping work place clean, which are discretionary behaviour of employees to keep the workplace clean; interpersonal harmony, which refers to employee actions aimed at facilitating and preserving harmonious relations in the workplace; protecting company resources, or efforts to save company resources, use personal resources to aid the company and protect the company from disasters in the workplace. These latter five dimensions were reported as emic in nature.

A study conducted in Japan (Yutaka \& Atsuko, 2011) yielded ten dimensions through a qualitatively sorting of items. Seven of the identified dimensions were aligned to those already found in studies conducted in the Western contexts (altruism, civic virtue, supporting students, courtesy, conscientiousness, sportsmanship and selfdevelopment) and three were identified as specific to Japan (maintaining harmonious relationships, mutual understanding, and maintaining a clean workspace).

In Sri Lanka, Rauf \& Kumar (2015) identified eight dimensions through content analytic methods. They are: conscientiousness, going beyond the minimum role requirements of the organization with respect to attendance, obeying rules and regulations, and dedication at work; altruism, willingness to help another person with his or her work or non-work related problem; civic virtue, acts of creativity and innovation to improve the organizational performance; defending, acts that create goodwill towards the organization by defending it against threats; self-training, behaviours designed to improve personal knowledge, skills, and abilities; sportsmanship, willingness to tolerate minor inconveniences, courtesy, actions aimed at preserving harmony and preventing problems with others; conservation of the organizations' property, actions that preserve property (see Rauf \& Kumar, 2015).

Thus, it is evident that the findings are confounded by the methods used. The use of techniques to establish equivalence seems to demonstrate consistency across settings. Even factor analyses of inductively generated items seem to yield a limited number of dimensions, which show substantial consistency across settings. In contrast, qualitative coding seems to yield a larger 
range of dimensions, which are sensitive to a greater extent than the previously described methods, to identify culture specific dimensions.

\section{THE EFFECTS ON METHODOLOGY ON OCB DIMENSIONALITY}

The methods used by researchers attempting to demonstrate equivalence are likely to show consistency in conceptualisations. On the other hand, researchers attempting to identify a culture specific conceptualisation are likely to identify these specificities. The authors could not find any studies that attempted to validate qualitatively derived dimensions using factor analysis. Review of the literature indicated that, while scales developed using the former procedures are frequently adopted by others, those that use qualitative classifications are not. Perhaps these latter dimensions do not translate well into the generally established methods of demonstrating equivalence, i.e., through factor analysis. Perhaps factor analysis does not yield the same structures that qualitative coding would, and the former may yield a more parsimonious and generalised conception that glosses over the nuances that qualitative approaches yield. On the other hand, perhaps factor analytically derived dimensions replicate across studies using factor analysis for validation purposes. However, these two perspectives provide valuable but different approaches to determine the content domains of constructs with etic approaches using theoretically derived conceptionalisations and emic approaches using the data itself to derive the content domain of OCB. Thus, both perspectives provide a different 'truth' regarding $\mathrm{OCB}$, which in the present literature is not easily integrated.

Two studies were conducted. Study 1 used Exploratory Factor Analysis (EFA) and Study 2 used both exploratory and Confirmatory Factor Analysis (CFA) to explore the dimensionality of OCB in Sri Lanka among academic staff members. A pool of items generated in Rauf \& Kumar (2015) was subjected to this process. The researchers hypothesised that factor analysis would yield a small set of factors that are consistent with existing conceptualisations of OCB. Both studies were based on samples of permanent (tenured) academic staff members from different universities in Sri Lanka but used slightly different procedures for data collection. Academic staff was chosen because of the high role discretion inherent in academic positions (Shazia \& Munazza, 2011) should result in a large variation in behaviour (Mischel, 1977). The questionnaires were administered in both Sinhala and Tamil languages.

\section{Study 1}

\section{Methods}

To measure each of the eight OCB dimensions reported in Rauf \& Kumar (2015), three to six items were identified. The items were based on the responses generated in Rauf \& Kumar (2015), where participants had been asked to provide instances of OCB, based on its definition, which were then content analysed and sorted to develop the final eight dimensions. The highly contextualised nature of the original items were retained to maintain specificity at the item level and to ensure consistency across the research.

Using this process, 38 items were created. All items were originally in English and translated into Sinhala and Tamil via a double blind back-translation technique. Each item was rated on a 7-point scale ranging from strongly disagree to strongly agree. In addition, information of the respondents' university and faculty, age, gender and years of service were also gathered.

First, the questionnaire was administered to a sample of 40 academics and minor modifications were made to ten items. The finalised measure was administered to a sample of 210 academicians representing different disciplines from two national universities. A stratified sampling technique, with strata based on university, faculty, gender, age and positions, was used. The sample consisted of 145 men and 65 women. The respondents' age averaged 36 years and ranged from 26 to 58 years. They had an average of 6.8 years on the job.

Data were collected through two modalities. One of the authors visited the universities and distributed hard copies of the questionnaire to participants. Later, questionnaires were sent through email for participants to return electronically. A cover letter accompanied each survey stating that participation was voluntary and anonymous in nature. Contact information was provided to participants in case of questions or concerns. The letter also provided a simple definition of OCB and the objectives of the study.

\section{Results}

EFA was conducted, using maximum likelihood extraction and an oblique rotation, which resulted in a 2 -factor solution that accounted for $71 \%$ of the variance, not the eight dimensional model derived by Rauf \& Kumar (2015). Six items which had smaller loadings $(<.40)$ were dropped from the model. While the initial model produced a chi-square goodness-of-fit index of $2580.80, \mathrm{df}=523, \mathrm{p}<.01$, the EFA with the final 32 items 
resulted in a chi-square of 1997.63, $\mathrm{df}=494, \mathrm{p}<.05$. Table 1 lists the 38 items, their loadings and the theoretical OCB category that each item was initially intended to measure. Items loading greater than .40 were classified as representing a particular factor. As a result, 18 items loaded on Factor 1 and 14 on Factor 2 (see Table 1). The resulting model supported the substantive categories of OCBO and OCBI. Reliability for both factors were high, $\alpha_{\mathrm{OCBI}}=.96$ and $\alpha_{\mathrm{OCB} 0}=.97$.

To conclude, the present study supports a two factor model of OCB that fits with Williams \& Anderson's (1991) OCBI-OCBO conceptualisation. The results also indicate that dimensions identified in Rauf \& Kumar (2015) fall neatly into the theoretically consistent Williams \& Anderson (1991) dimensions.

While the present study used exploratory methods to identify the underlying structure, literature suggests that a more robust method of examining factor structures would be to test a structure that is developed a-priori (Treiblmaier \& Filzmoser, 2010). As CFA requires a larger sample size than available from Study 1 (see Bentler \& Chou, 1988), the next study, using a larger sample, attempts to replicate the results of Study 1 and uses CFA, in addition to EFA, to test model fit.

Table 1: Results of Exploratory Factor Analysis of OCB Scales

\begin{tabular}{|c|c|c|c|c|c|c|c|}
\hline \multirow[t]{2}{*}{ Items } & \multirow[t]{2}{*}{$\begin{array}{r}\text { Hypothesised OCB } \\
\text { Dimensions }\end{array}$} & \multirow{2}{*}{$\begin{array}{r}\text { OCB } \\
\text { Category } \\
\text { Broad }\end{array}$} & \multicolumn{2}{|c|}{$\begin{array}{l}\text { Factors } \\
\text { Study } 1\end{array}$} & \multicolumn{2}{|c|}{$\begin{array}{l}\text { Factors } \\
\text { Study } 2\end{array}$} & \multirow[t]{2}{*}{ Dropped Items } \\
\hline & & & 1 & 2 & 1 & 2 & \\
\hline Tolerate inconvenience when it arises & Sportsmanship & OCBO & .84 & .11 & .84 & .13 & \\
\hline $\begin{array}{l}\text { Try to make the best of the situation even when } \\
\text { there are problems }\end{array}$ & Sportsmanship & OCBO & .86 & .02 & .88 & -.03 & \\
\hline $\begin{array}{l}\text { Complain about insignificant issues present at } \\
\text { work }^{(\mathrm{r})}\end{array}$ & Sportsmanship & OCBO & .90 & .06 & .90 & -.08 & \\
\hline $\begin{array}{l}\text { Defend University when people find fault with } \\
\text { it }\end{array}$ & Defending & $\mathrm{OCBO}$ & .89 & .20 & .88 & -.21 & \\
\hline Do not talk about the good aspects of the & Defending & $\mathrm{OCBO}$ & .67 & .11 & .69 & .16 & Dropped in \\
\hline $\begin{array}{l}\text { University to outsiders }{ }^{(\mathrm{r})} \\
\text { Do not show pride when representing the } \\
\text { University in public }^{(\mathrm{r})}\end{array}$ & Defending & OCBO & .69 & .15 & .71 & .16 & $\begin{array}{l}\text { Study } 2 \text { CFA } \\
\text { Dropped } \\
\text { in Study } 2 \text { CFA }\end{array}$ \\
\hline $\begin{array}{l}\text { Comply with instructions even when the Head } \\
\text { is absent }\end{array}$ & Conscientious Behaviour & $\mathrm{OCBO}$ & .82 & .09 & .83 & .09 & \\
\hline Do my best not to make students wait & Conscientious Behaviour & $\mathrm{OCBO}$ & .85 & .02 & .84 & -.01 & \\
\hline $\begin{array}{l}\text { Follow the University rules (such as returning } \\
\text { library books on time) }\end{array}$ & Conscientious Behaviour & OCBO & .89 & .07 & .89 & -.08 & \\
\hline Use resources properly without wastage & Conservation of property & OCBO & .91 & .15 & .90 & -.16 & \\
\hline $\begin{array}{l}\text { Try to preserve University property whenever } \\
\text { possible }\end{array}$ & Conservation of property & OCBO & .68 & .16 & .69 & .17 & $\begin{array}{l}\text { Dropped } \\
\text { in Study } 2 \text { CFA }\end{array}$ \\
\hline Not harm University property & Conservation of property & $\mathrm{OCBO}$ & .90 & .16 & .89 & -.14 & \\
\hline $\begin{array}{l}\text { Subscribe to and read professional journals } \\
\text { related to my work }\end{array}$ & Self-development & OCBO & .81 & .12 & .82 & .12 & \\
\hline $\begin{array}{l}\text { Participate in job related courses even though } \\
\text { they are not required }\end{array}$ & Self-development & OCBO & .88 & .01 & .88 & -.02 & \\
\hline $\begin{array}{l}\text { Acquire knowledge and skills in new areas that } \\
\text { contribute to my work }\end{array}$ & Self-development & OCBO & .85 & .06 & .86 & .07 & \\
\hline $\begin{array}{l}\text { Am up to date on the development of the } \\
\text { University at large and make use of the new } \\
\text { development }\end{array}$ & Individual Initiative & $\mathrm{OCBO}$ & .88 & .00 & .89 & -.03 & \\
\hline $\begin{array}{l}\text { Manage difficult work assignments while } \\
\text { maintaining interest }\end{array}$ & Individual Initiative & $\mathrm{OCBO}$ & .84 & .04 & .85 & .03 & \\
\hline Attend meetings regularly & Individual Initiative & $\mathrm{OCBO}$ & .77 & .18 & .78 & .05 & $\begin{array}{l}\text { Dropped } \\
\text { in Study } 2 \text { CFA }\end{array}$ \\
\hline
\end{tabular}

Continued- 
Continued from page 70

\begin{tabular}{|c|c|c|c|c|c|c|c|}
\hline Help other staff in need & Altruism & OCBI & .07 & .82 & .06 & .82 & \\
\hline Voluntarily assist others in their job & Altruism & OCBI & .08 & .83 & .07 & .83 & \\
\hline $\begin{array}{l}\text { Adjust my work schedule to accommodate } \\
\text { other employees' requests }\end{array}$ & Altruism & OCBI & .12 & .77 & .14 & .76 & \\
\hline $\begin{array}{l}\text { Assist the Head with his/her job even when not } \\
\text { asked to do so }\end{array}$ & Altruism & OCBI & .20 & .77 & .21 & .77 & \\
\hline Am always prepared to help students & Altruism & OCBI & .12 & .84 & .12 & .86 & \\
\hline $\begin{array}{l}\text { Am always prepared to respond to } \\
\text { questionnaires }\end{array}$ & Altruism & OCBI & .14 & .80 & .13 & .81 & \\
\hline $\begin{array}{l}\text { Pass important information to other staff } \\
\text { members }\end{array}$ & Altruism & OCBI & .07 & .83 & .06 & .84 & \\
\hline Express opinions without bias & Courtesy & OCBI & .00 & .87 & -.02 & .88 & \\
\hline $\begin{array}{l}\text { Accept others' comments and respect ideas of } \\
\text { others }\end{array}$ & Courtesy & OCBI & .01 & .78 & & & \\
\hline $\begin{array}{l}\text { Show genuine concern and courtesy toward } \\
\text { others }\end{array}$ & Courtesy & OCBI & .00 & .83 & .00 & .82 & \\
\hline $\begin{array}{l}\text { Attack staff members' opinion for putting them } \\
\text { down }^{(\mathrm{r})}\end{array}$ & Courtesy & OCBI & .14 & .80 & -.14 & .79 & \\
\hline $\begin{array}{l}\text { Ask questions intentionally at meetings to hurt } \\
\text { others and damage their image }^{(r)}\end{array}$ & Courtesy & OCBI & .16 & .76 & .15 & .77 & \\
\hline $\begin{array}{l}\text { Am careful about the effect of my behaviour on } \\
\text { another's job }\end{array}$ & Courtesy & OCBI & .25 & .84 & -.24 & .84 & \\
\hline Exercise personal discipline and self-control & Courtesy & OCBI & .40 & .84 & -.39 & .84 & \\
\hline $\begin{array}{l}\text { Keep up with new proposals for educational } \\
\text { development }\end{array}$ & Self-development & OCBO & .25 & .00 & -- & -- & $\begin{array}{l}\text { Dropped in } \\
\text { Study } 1\end{array}$ \\
\hline $\begin{array}{l}\text { Go to the University on holidays for special } \\
\text { work }\end{array}$ & $\begin{array}{l}\text { Conscientiousness } \\
\text { Behaviour }\end{array}$ & OCBO & .03 & .17 & -- & -- & $\begin{array}{l}\text { Dropped in } \\
\text { Study } 1\end{array}$ \\
\hline $\begin{array}{l}\text { Keep up with University procedures and } \\
\text { standards }\end{array}$ & $\begin{array}{l}\text { Conscientiousness } \\
\text { Behaviour }\end{array}$ & OCBO & .20 & .23 & -- & -- & $\begin{array}{l}\text { Dropped in } \\
\text { Study } 1\end{array}$ \\
\hline $\begin{array}{l}\text { Comply with the code of ethics in performing } \\
\text { academic and examination work }\end{array}$ & $\begin{array}{l}\text { Conscientiousness } \\
\text { Behaviour }\end{array}$ & OCBO & .19 & .19 & -- & -- & $\begin{array}{l}\text { Dropped in } \\
\text { Study } 1\end{array}$ \\
\hline $\begin{array}{l}\text { Misuse the University property and equipment } \\
(\mathrm{r})\end{array}$ & $\begin{array}{l}\text { Conserve the University } \\
\text { property }\end{array}$ & OCBO & .05 & .12 & -- & -- & $\begin{array}{l}\text { Dropped in } \\
\text { Study } 1\end{array}$ \\
\hline $\begin{array}{l}\text { Take credit due to others, and fight for } \\
\text { improper personal gain }{ }^{(r)}\end{array}$ & Self-discipline & OCBI & .14 & .19 & -- & -- & $\begin{array}{l}\text { Dropped in } \\
\text { Study } 1\end{array}$ \\
\hline
\end{tabular}

Note: OCBO: Organizational Citizenship Behaviour that benefit the Organization

OCBI : Organizational Citizenship Behaviour that immediately benefits other individuals and indirectly contributes to the Organization (r) : Item was reverse coded

\section{Study 2}

The previous study examined the factor structure of the OCB construct and revealed a two factor model, consistent with Williams \& Anderson's (1991) dimensions of $\mathrm{OCB}$ directed towards the organization (OCBO) and $\mathrm{OCB}$ directed towards the individual (OCBI). This study further validates the factor structure of OCB through using EFA and then testing the model using Confirmatory Factor Analysis (CFA) on a new and bigger sample.

\section{Method}

The sample was of academic staff members drawn from three Sri Lankan state universities, which represent three groups of universities classified according to when they were established (50, 30 and 20 years ago). A stratified random sampling method, using strata based on gender, position and university, was used to select participants. A sample of 193 men and 107 women, $N=300$, from various faculties, was identified. Their ages averaged 36 years and ranged from 26 to 63 years. Average tenure 
was 8.3 years. With 32 indicators, the sample size to indicator ratio was acceptable (Bentler \& Chou, 1988). Due to incomplete data, 36 cases were discarded. A final set of 264 cases was used.

\section{Results}

First EFA revealed very similar loading from Study 2 as with Study 1 (see Table 1). Next, CFA was used to examine the fit of the two-factor model derived from Study 1 . In confirmatory factor analysis, the covariance matrix is used and fit indices are calculated. Initially, the two factor model was specified using the 32 items and maximum likelihood techniques were used to estimate the model. For TLI, GFI and CFI, values greater than .95 constitute good fit and values greater than .90 acceptable fit (Medsker et al., 1994). For the RMSEA, values less than .05 constitute good fit, values between .05 and .08 are considered acceptable fit, values between .08 to .10 reflect marginal fit and values greater than .10 reflect poor fit (Browne \& Cudeck, 1992). The initial analyses yielded low values of fit with a Chi-square of $2614.05(d f=344), \mathrm{p}<.001$ and $\mathrm{GFI}=.72, \mathrm{CFI}=.80$, $\mathrm{TLI}=.87, \mathrm{RMSEA}=.14$, suggesting poor fit. Therefore, modification indices and residuals were examined and, as a result, four items were dropped and four sets of error variances were allowed to co-vary. This resulted in a significant improvement in model fit. The two factor model, measured by 28 items, resulted in a Chi-square of $1702.36(d f=293), p<.001$, and $\mathrm{GFI}=.91, \mathrm{CFI}=.93$, $\mathrm{TLI}=.91, \mathrm{RMSEA}=.07$ (see Figure 1 for final parameter estimates), suggesting acceptable fit.

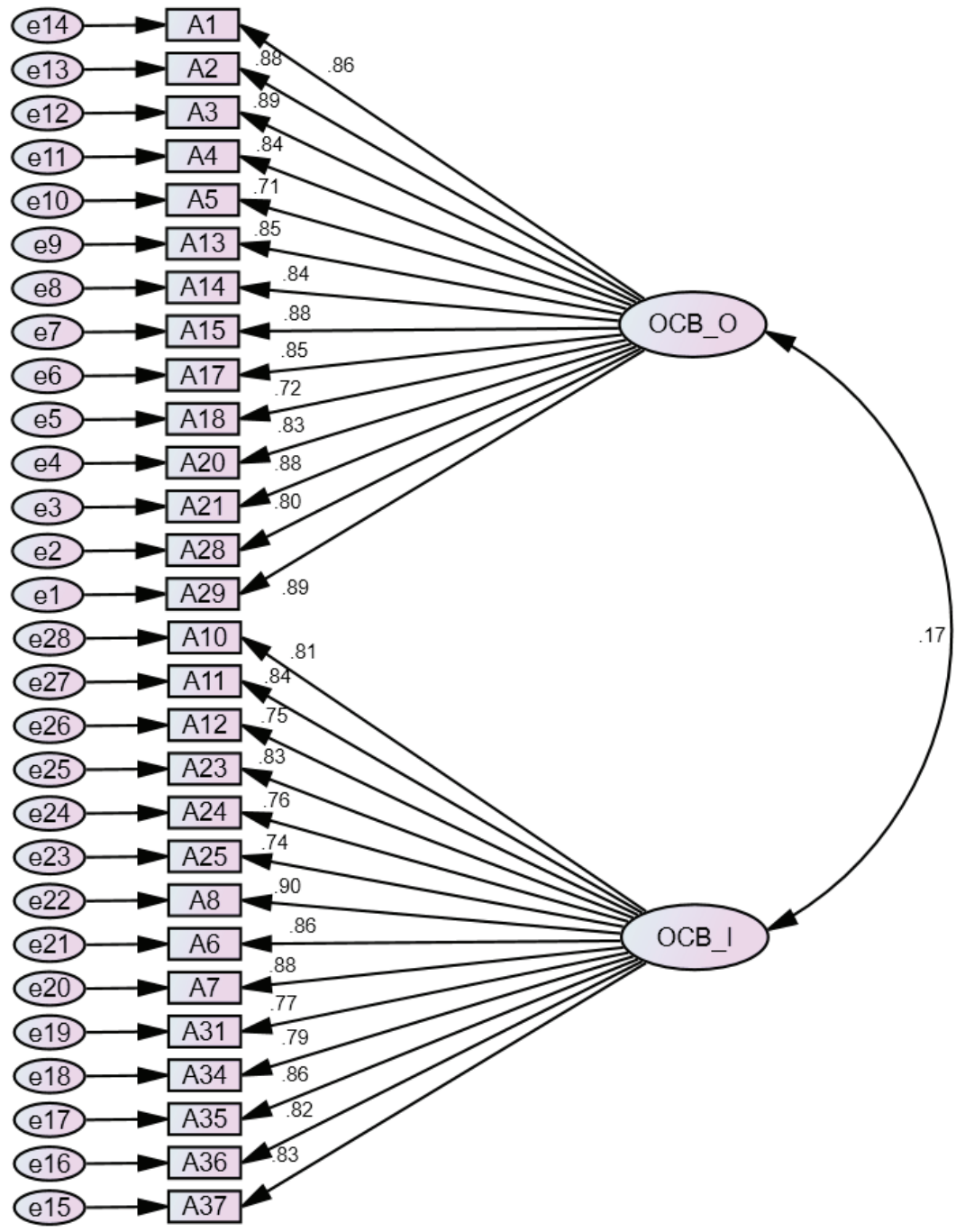

Figure 1: Path diagram for the two-factor structure (CFA) 


\section{DISCUSSION AND CONCLUSIONS}

The present studies support the Williams \& Anderson's (1991) two dimensional model of OCB and add to the substantial literature on the OCBO-OCBI distinction. This study contributes to the literature on OCB by finding support for the Williams \& Anderson model in an instance, where the items were highly context specific and were designed to capture another set of dimensions derived from that same context. In other words, even though the items and dimensions were designed to test a more complex alternative, hypothesised model, the results were consistent with a simpler pre-existing model of OCB. The researchers were able to replicate the two dimensional model across two studies.

This paper follows up on Rauf \& Kumar (2015) to investigate the dimensionality of $\mathrm{OCB}$ in university teachers in the Sri Lankan context. For this purpose, two studies were conducted. Study 1 used Exploratory Factor Analysis (EFA) and Study 2 used both exploratory (EFA) and Confirmatory Factor Analysis (CFA). Although the studies supported Williams \& Anderson's (1991) two factor conceptualisation of OCB, and not Rauf \& Kumar's (2015) eight dimensional model, the items designed to test the Rauf \& Kumar (2015) dimensions fell neatly into OCBO or OCBI in a theoretically consistent manner. It is possible that factor analysis is not sensitive to subtle differences between dimensions that are captured through item sorting methods and that factor analysis captures a broader bandwidth (Ones et al., 1993). Alternatively, perhaps sorting methods are highly contextual and not easily captured through follow up research attempting to replicate these dimensions. In other words, the OCB structure may depend on the method of investigation, with nuances specific to the context captured through highly contextualised qualitative methods and broader dimensions captured through factor analysis.

With respect to the question of whether conceptualisations are easily transferrable from location to location, the present study supports a body of literature on personality that suggests the affirmative (McCrae et al., 2005). The present research found that a simpler model of OCB was captured even in an instance where the items were highly contextualised. However, the study also suggests that the original context specific conceptualisation is meaningful as the items designed to measure those dimensions were incorporated into broader dimensions in a theoretically meaningful manner. Therefore, the question of which level of specificity is important in a given context becomes important. At times, greater specificity may be important so that the model is able to address the nuances of the context. At other times, such as when cross national comparisons are called for, broader dimensions seem appropriate (Kashima, 2016).

The theoretical physicist and Nobel Laureate, Werner Heisenberg, in highlighting how the methodology and questions adopted in research affect findings, stated "What we observe is not nature itself, but nature exposed to our method of questioning" (Heisenberg, 2000/1958: p. 25). Similarly, regarding social phenomena, the findings suggest that perhaps the two approaches, emic and etic, have a propensity to elicit results that are consistent with the paradigm the research adopts. This researchers' results provide a possible means through which findings from emic and etic approaches to understanding the conceptualisation of constructs can be synthesised to arrive at the final goal of such research, which is to develop a more comprehensive understanding of a phenomenon that is able to integrate generalisations and specificities and is able to build on each other. Which approach is relevant would depend on the lens through which OCB is viewed.

In these two studies, the authors used the term context to refer to Sri Lankan university teachers and as such 'context' may be interpreted to refer to the fact that the study was conducted in Sri Lanka, at Sri Lankan universities, or with academic staff at Sri Lankan universities. In the cross-cultural literature, it is not uncommon to study a specific subset of individuals to derive an understanding of the 'cultural' context, which is then frequently used as a proxy for those represented in the country. Hofstede's (1980) work is a classic example of such research. This study did not make such a generalisation as it was deemed unwarranted as the study simply explores a measure derived from an explicitly specific sample located within specific work and national contexts. The researchers did not approach this study assuming that the dimensionality found in this study would generalise to other broader contexts outside of academic staff at Sri Lankan universities. However, the fact that these findings suggest that a model found elsewhere fits this very specific context even when the items were designed to assess other dimensions, provides support to the robustness of Williams \& Anderson's (1991) model.

\section{REFERENCES}

Anuja, R. (2016) Organizational Citizenship Behavior in Schools: Special Reference to Schools in Trincomalee District in Sri Lanka, European Journal of Business and Management, 8 (3), pp: 72-76 [Online] Available from: https://www. researchgate.net/publication/317088883_Organizational_ 
Citizenship_Behavior_in_Schools_Special_Reference_to_ Schools_in_Trincomalee_District_in_Sri_Lanka [Accessed: 04 ${ }^{\text {th }}$ November 2018].

DOI: https://doi.org/10.4038/jbs.v4i1.16

Bentler, P. M. and Chou, C. (1988) Practical Issues in Structural Modelling, In Long, J. S. (eds.) Common Problems/proper Solutions: Avoiding Error in Quantitative Research, pp: 92161, Newbury Park, California: Sage.

Berry, J. W. (1969) On cross-cultural comparability, International Journal of Psychology, 4(2), pp: 119-128.

Boiral, O. (2009) Greening the corporation through organizational citizenship behaviors, Journal of Business Ethics, 87(2), pp: 221-236.

DOI: https://doi.org/10.1007/s10551-008-9881-2

Bourdage, J. S., Lee, K., Lee, J. H. and Shin, K. H. (2012) Motives for organizational citizenship behavior: Personality correlates and coworker ratings of OCB, Human Performance, 25(3), pp: 179-200.

DOI: https://doi.org/10.1080/08959285.2012.683904

Browne, M. W. and Cudeck, R. (1992) Alternative ways of assessing model fit, Sociological Methods and Research, 21(2), pp: $230-258$.

DOI: https://doi.org/10.1177/0049124192021002005

Chakkarath, P. (2012) The role of indigenous psychologies in the building of basic cultural psychology, In Valsiner, J. (ed.) The Oxford Handbook of Culture and Psychology, pp: 71-95, New York: Oxford University Press.

D O I : h t t p s : / / d o i.org/ 10 . $1093 /$ oxfordhb/9780195396430.013.0005

Dalal, R. S. (2005) A meta-analysis of the relationship between organizational citizenship behavior and counterproductive work behaviour, Journal of Applied Psychology, 90(6), pp: 1241-1255.

DOI: https://doi.org/10.1037/0021-9010.90.6.1241

Farh, J. L., Zhong, C. B. and Organ, D. W. (2004) Organizational citizenship behaviour in the People's Republic of China, Organization Science, 15(2), pp: 241-253.

DOI: https://doi.org/10.1287/orsc.1030.0051

Farh, J. L., Zhong. C. B. and Organ. D. W. (2002) An inductive analysis of the construct domain of organizational citizenship behaviour, In Tsui, A. S. and Lau, C. M. (eds.) The Management of Enterprises in the People's Republic of China, pp: 445-470, Boston: Kluwer Academic Press.

DOI: https://doi.org/10.1007/978-1-4615-1095-6_18

Farh, P., Christopher, E. and Shu-Chi, L. (1997) Impetus for action: A cultural analysis of justice and organizational citizenship behavior in Chinese society, Administrative Science
Quarterly, 42(3), pp: 421-444.

DOI: https://doi.org/10.2307/2393733

Finkelstein, M. A. and Penner, L. A. (2004) Predicting organizational citizenship behavior: Integrating the functional and role identity approaches, Social Behavior and Personality, 32(4), pp: 383-398.

DOI: https://doi.org/10.2224/sbp.2004.32.4.383

Finkelstein, M. A. (2006) Dispositional predictors of organizational citizenship behavior: motives, motive fulfillment, and role identity, Social Behavior and Personality: An International Journal, 34(6), pp: 603-616.

DOI: https://doi.org/10.2224/sbp.2006.34.6.603

Graen, G. B. (1976) Role making processes within complex organizations, In Dunnette, M. D. (ed.) Handbook of Industrial and Organizational Psychology, pp: 1201-1245, Chicago, Illinois: Rand McNally.

Heisenberg, W. (2000) Physics and philosophy: The revolution in modern science, London: Penguin.

Ho, D. Y. F. and Wu, M. (2001) Introduction to cross-cultural psychology, In Adler, L. L. and Gielen, U. P. (eds.) Crosscultural Topics in Psychology, pp: 3-13, Westport, Connecticut: Praeger.

Hofstede, G. (1980) Culture's consequences: International differences in work-related values, Beverly Hills, California: Sage.

DOI: https://doi.org/10.1177/017084068300400409

Hui, C. H. and Triandis, H. C. (1985) Measurement in crosscultural psychology: a review and comparison of strategies, Journal of Cross-Cultural Psychology, 16, pp: 131-152.

DOI: https://doi.org/10.1177/0022002185016002001

Kashima, Y. (2016) Culture and psychology in the $21^{\text {st }}$ century: Conceptions of culture and person for psychology revisited, Journal of Cross-Cultural Psychology, 47, pp: 4-20.

DOI: https://doi.org/10.1177/0022022115599445

Katz, D. and Kahn, R. L. (1966) The Social Psychology of Organizations, New York: Wiley.

Kumar, K. and Bakhshi, A. (2009) Organizational citizenship behaviour in India: Development of a scale, International Journal of Organizational Behaviour, 14, pp: 14-25.

Lam, S. S. K., Hui, C. and Law, K. S. (1999) Organizational citizenship behaviour: Comparing perspectives of supervisors and subordinates across four international samples, Journal of Applied Psychology, 84(4), pp: 594-601.

DOI: https://doi.org/10.1037//0021-9010.84.4.594

Lam, W., Chen, Z. and Takeuchi, N. (2009) Perceived human resource management practices and Intention to Leave of 
Employees: The mediating role of organizational citizenship behaviour in a Sino -Japanese Joint venture, The International Journal of Human Resource Management \& Information Technology, 20(11), pp: 2250-2270.

DOI: https://doi.org/10.1080/09585190903239641

McCrae, R. R., Terracciano, A. and 78 Members of the Personality Profiles of Cultures Project (2005) Universal features of personality traits from the observer's perspective: data from 50 cultures, Journal of Personality and Social Psychology, 88(3), pp: 547-561.

DOI: https://doi.org/10.1037/0022-3514.88.3.547

Medsker, G. J., Williams, L. J. and Holahan, P. J. (1994) A review of current practices for evaluating causal-models in organizational behavior and human resources management research, Journal of Management, 20(2), pp: 439-464.

DOI: https://doi.org/10.1016/0149-2063(94)90022-1

Mischel, W. (1977) The interaction of person and situation, In Magnusson, D. and Endler, N. S. (eds.) Personality at the crossroads: Current issues in interactional psychology, Hillsdale, New Jersey: Erlbaum.

Nohe C. and Michaelis, B. (2016) Team OCB, leader charisma, and organizational change: a multilevel study, The Leadership Quarterly, 27(6), pp: 883-895.

DOI: https://doi.org/10.1016/j.leaqua.2016.05.006

Norenzayan, A. and Heine, S. J. (2005) Psychological universals: What are they and how can we know?, Psychological Bulletin, 131(5), pp: 763-784.

DOI: https://doi.org/10.1037/0033-2909.131.5.763

Ones, D. S., Viswesvaran, C. and Schmidt, F. L. (1993) Comprehensive meta-analysis of integrity test validities: Findings and implications for personnel selection and theories of job performance, Journal of Applied Psychology, 78(4), pp: 679-703.

DOI: https://doi.org/10.1037//0021-9010.78.4.679

Organ, D. W. and Paine, J. B. (1999) A new kind of performance for industrial and organizational psychology: Recent contributions to the study of organizational citizenship behaviour, In Cooper, C. L. and Robertson, I. T. (eds.) International Review of Industrial and Organizational Psychology, 14, pp: 337-368.

DOI: https://doi.org/10.1002/0470013346

Organ, D. W. (1988) Organizational citizenship behaviour: The good soldier syndrome, Lexington, Massachusetts: Lexington Books.

Organ, D. W. (1997) Organizational citizenship behavior: It's construct cleanup time, Human Performance, 10(2), pp: 85-97. DOI: https://doi.org/10.1207/s15327043hup1002_2
Organ, D. W., Podsakoff, P. M. and MacKenzie S. P. (2006) Organizational citizenship behavior: Its nature, antecedents, and consequences, London: Sage.

Podsakoff, N. P., Whiting, S. W., Podsakoff, P. M. and Blume, B. D. (2009) Individual- and organizational level consequences of organizational citizenship behaviours: A meta-analysis, Journal of Applied Psychology, 94(1), pp: 122-141.

DOI: https://doi.org/10.1037/e518442013-522

Podsakoff, P. M., MacKenzie, S. B., Moorman, R. H. and Fetter, R. (1990) Transformational leader behaviours and their effects on followers' trust in leader, satisfaction, and organizational citizenship behaviours, The Leadership Quarterly, 1(2), pp: 107-142.

DOI: https://doi.org/10.1016/1048-9843(90)90009-7

Podsakoff, P. M., MacKenzie. S. B., Paine. J. B. and Bachrach, D. G. (2000) Organizational citizenship behaviours: A critical review of the theoretical and empirical literature and suggestions for future research, Journal of Management, 26(3), pp: 513-563.

DOI: https://doi.org/10.1177/014920630002600307

Ratner, C. (2008) Cultural psychology, cross-cultural psychology and indigenous psychology, New York: Nova.

Rauf, F. H. A. and Kumar, S. (2015) The Emic and Etic Conceptualizations of Organizational Citizenship Behaviour (OCB): Exploring Sri Lankan university lecturers perceptions of their work, South Asian Journal Human of Resource Management, 2(2), pp: 123-138.

DOI; https://doi.org/10.1177/2322093715599276

Rauf, F. H. A. (2015a) What role does job satisfaction play on the relationship between organizational justice perception and organizational citizenship behavior? Empirical evidence from Sri Lankan employees, European Journal of Business and Management, 7(15), pp: 149-168.

Rauf, F. H. A. (2015b) Twenty first century human resource management practices: Why does organizational justice matter? An examination of effect of perception of organizational injustice on work alienation and organizational citizenship behaviour, International Journal of Engineering Research and Management, 2(8), pp: 94-100.

Rauf, F. H. A. (2014) Perception of organizational justice as a predictor of organizational citizenship behavior: An empirical study at schools in Sri Lanka, European Journal of Business and Management, 6(12), pp: 124-130 [Online] Available from: https://www.iiste.org/Journals/index.php/EJBM/article/ view/12527 [Accessed: 04 ${ }^{\text {th }}$ November 2018].

Rauf, F. H. A. (2013) Role work family conflict self-efficacy on the negative effect of organizational citizenship behaviour, South East Asia Journal of Contemporary Business, Economics and Law, 3(1), pp: 49-54. 
Rioux, S. M. and Penner, L. A. (2001) The causes of organizational citizenship behavior: A motivational analysis, Journal of Applied Psychology, 86(6), pp: 1306-1314.

DOI: https://doi.org/10.1037//0021-9010.86.6.1306

Shazia, Z. and Munazza, A. (2011) Relationship between occupational stress (0S) and organizational citizenship behaviour (OCB) of academic staff working at higher educational level, Elixir International Journal Soc. Sci., 40, pp: 5357-5362 [Online] Available from: https://www. elixirpublishers.com/articles/1350642377_40\%20(2011)\%20 5357-5362.pdf [Accessed: $4^{\text {th }}$ November 2018].

Smith, C. A., Organ, D. W. and Near, J. P. (1983) Organizational citizenship behavior: Its nature and antecedents, Journal of Applied Psychology, 68(4), pp: 653-663.

DOI: https://doi.org/10.1037//0021-9010.68.4.653

Sun, L-Y., Aryee, S., and Law, K. S. (2007) High-performance human resource practices, citizenship behaviour and organizational performance: A relational perspective, Academy of Management Journal, 50(3), pp: 558-577.

DOI: https://doi.org/10.5465/amj.2007.25525821

Takeuchi, R., Bolino, M. C. and Lin, C. C. (2015) Too many motives? The interactive effects of multiple motives on organizational citizenship behaviour, Journal of Applied Psychology, 100(4), pp: 1239-1248.

DOI: https://doi.org/10.1037/ap10000001

Treiblmaier, H. and Filzmoser, P. (2010) Exploratory factor analysis revisited: How robust methods support the detection of hidden multivariate data structures in IS research, Information and Management, 47(4), pp: 197-207.

DOI: https://doi.org/10.1016/j.im.2010.02.002

Weikamp, J. G. and Göritz, A. S. (2016) Organizational citizenship behaviour and job satisfaction: The impact of occupational future time perspective, Human Relations, 69(11), pp: 2091-2115.

DOI: https://doi.org/10.1177/0018726716633512

Wickramasinghe, V. and Perera, S. (2014) Effects of perceived organization support, employee engagement and organization citizenship behavior on quality performance, Total Quality Management \& Business Excellence, 25(11-12), pp: 12801294.

DOI: https://doi.org/10.1080/14783363.2012.728855

Williams, L. J. and Anderson, S. E. (1991) Job satisfaction and organizational commitment as predictors of organizational citizenship and in-role behaviours, Journal of Management, 17(3), pp: 601-617.

DOI: https://doi.org/10.1177/014920639101700305

Yutaka, U. and Atsuko, Y. (2011) Establishment of Japanese Organizational Citizenship Behaviour Dimensions, Journal of the Faculty of Economics, 42(1), pp: 19-36 [Online] Available from: http://repository.seikei.ac.jp/dspace/ bitstream/10928/78/1/keizai-42-1_19-36.pdf [Accessed: $4^{\text {th }}$ November 2018].

Zhao, H., Wu, J., Sun, J. and Chen, C. W. (2012) Organizational citizenship behaviour in Chinese society: a re-examination, The International Journal of Human Resource Management, 23(19), pp: 4145-4165. 